\title{
ПЕРСПЕКТИВЫ РАЗВИТИЯ СИСТЕМЫ ВЫСШЕГО ОБРАЗОВАНИЯ АРМЕНИИ: ГУМАНИЗАЦИЯ ИЛИ ГУМАНИТАРИЗАЦИЯ?
}

\author{
Берберян А. С. (Российско-Армянский университет, Ереван, Армения) \\ aspsy@inbox.ru
}

\begin{abstract}
В статье рассматриваются гуманистические подходы к образовательной политике Армении. Утверждается идея о том, что более продуктивное личностное и профессиональное развитие специалистов может быть обеспечено введением в образовательный процесс вуза составляющей личностноразвивающего образования. Целью нашего исследования является выявление готовности субъектов образовательной деятельности к гуманизации, личностно ориентированной деятельности. Результаты проведенных эмпирических исследований свидетельствуют о необходимости выявления параметров сформированности готовности гуманистической позиции субъектов образовательной деятельности.
\end{abstract}

Ключевые слова: гуманизация, гуманитаризация, система высшего образования, преподаватели и студенты, сформированность готовности гуманистической позиции.

В последнее время образование в Армении, особенно высшее, начинает рассматриваться как ведущий, наиболее действенный фрактор, определяющий результативность всех процессов выживания общества - не только духовных, но и социально-экономических. Причиной такого внимания является понимание того, что в нынешних условиях образование может обеспечить возрождение интеллектуального и творческого потенциала нации. Образовательная сфера это та основа, которая в развитых странах приносит до 45-45 \% прироста валового национального продукта и в конечном счете обеспечивает поступательное развитие государства [8]. Армения, имея ограниченные природные и инвестиционные ресурсы, должна опираться на образование как на источник и самое эфффективное средство прогресса, самый мощный инвестиционный ресурс.

В системе высшего профессионального образования республики за последние годы, как и в остальных странах Содружества Независимых Государств, объективные экономические процессы, связанные с развитием рыночных отношений и их активным внедрением в образовательную сферу, стимулируют рост спроса образовательных услуг. Все более широкие слои населения осознают, что высшее образование дает наиболее реальную возможность иметь престижную и высокооплачиваемую работу, занимать более достойное место в обществе. 
Армения пошла по пути осуществления реформ в области образования. Основной целью проводимых реформ является приведение системы образования в Армении в соответствие с европейской системой, формирование национальной системы квалификации образования и фрормирование институциональных изменений.

Новые, гуманистические подходы к образовательной политике Армении нашли отражение в законе “Об образовании», принятом в 1999 году, который дает определенный вектор образовательной политики, создает гуманистическую основу для фрормирования современной системы высшего образования. Закон РА «Об образовании» установил принципы государственной политики в области образования: гуманистический характер образования, приоритет общечеловеческих ценностей, жизни и здоровья человека, свободного и всестороннего развития личности, воспитание гражданского сознания, национального достоинства, патриотизма, законности и экологического мировоззрения и др. [10].

Переход к новой парадигме образования, несмотря на общую «принятость» и декларируемость, остается во многих образовательных учреждениях лишь позитивным вектором развертывания работы. Ее углубленная разработка в соответствии с задачами конкретного образовательного учреждения затруднена в связи с тем, что большая часть педагогов, работающих в системе высшего образования, получили профессиональную подготовку и приобрели опыт работы в традиционной, «знаниевой» парадигме, и поэтому они испытывают затруднения В осуществлении личностноразвивающего образования. В практическом исследовании, проведенном с преподавателями высшей школы государственных и негосударственных учреждений (общим количеством 186 человек) 87 \% признали приверженность традиционной системе обучения, невозможность, непривычность нетрадиционных, инновационных методов преподавания [1].

Анализ государственных стандартов и учебных программ по подготовке специалистов: психологов, журналистов, экономистов и др. и реального состояния преподавания позволяет сделать выводы о значительных расхождениях между образовательной ситуацией в Армении, сложившейся к началу XXI века, и уровнем отражения в ней личностно-развивающей парадигмы образования. Попытки разрешить это противоречие в Армении неоднократно предпринимались теоретиками и практиками образовательной сферы.

Более продуктивное личностное и профессиональное развитие специалистов может быть обеспечено введением в образовательный процесс вуза составляющей личностноразвивающего образования. Наиболее фундаментальной и конструктивной концепцией, выступающий как внутренняя система саморегуляции, представляется личностно-центрированный подход К. Род- 
жерса к развитию личности. Реализация образовательного сценария модели личностно-центрированного образования для Армении является оптимальным способом развития. По формальным признакам Армения принадлежит к православной ветви евро-атлантической цивилизации. Геополитическое положение Армении рассматривается как форпост христианской цивилизации. Истинно христианские ценности, такие, как милосердие, доброта, гуманизм, принятие человека, любовь к ближнему - изначально являются присущими, значимыми и ключевыми для армянской ментальности.

По нашему мнению, ценностной основой, содержанием образовательной системы, в частности, высшей школы, для Армении может стать гуманистическое образование, которое направлено на развитие нравственных ценностей личности и ориентирует преподавателя на самоорганизацию педагогической деятельности, позволяющей наполнить личностным смыслом [2].

Главная причина психолого-педагогических погрешностей и упущений отсутствие четкой цельной структуры гуманистической, по преимуществу самоорганизуемой учебно-воспитательной системы. Высшее образование традиционно расценивает студентов как объектов деятельности, на которых оказывается воздействие; не доверяет студентам и не верит в их возможность самостоятельно мыслить, быть креативной личностью, предпочитает «загружать» память, а не развивать самосознание.

В основе существующих личностно-центрированных технологий являются концепции известных психологов Б. Г. Ананьева, А. Г. Асмолова, А. Н. Леонтьева, Д. А. Леонтьева, в том числе экзистенциально-гуманистические концепции А. Маслоу, К. Роджерса, Г. Оллпорта Г., В. Франкла, Э. Фромма, Дж. Бьюдженталя и др. Вопросы перехода от традиционной парадигмы к личностно-центрированному обучению отражены в работах А В. В. Серикова, И. С. Якиманской, Г. К. Селевко, И. В. Абакумовой, П. Н. Ермакова.

Дело заключается в том, что новые веяния, такие, как информатизация и технократизация, именуемая «фундаментализацией», принципиально не меняют содержательное наполнение системы образования. Однако гуманизация (лат. humanitas - «человечность») - жизненная позиция, согласно которой люди имеют право на личностное самоопределение и свободное волеизъявление.

Гуманизация образования подтверждает фракт, что ядром личности является ее субъектная, нравственно-творческая составляющая, а сам педагогический процесс - гуманистический френомен [5,7]. Создаваемые в настоящее время творческие образовательные модели являются свидетельством становлении гуманистической парадигмы образования. Данная парадигма ориентирована на развитие личности, на раскрытие потенциала человека творческого, мыслящего, активного субъекта деятельности. 
Парадоксальность феномена заключается в путанице понятий «гуманизация» и «гуманитаризация». Система реформирования утверждает гуманистические ориентиры в основном и прежде всего посредством предметоцентризма, т.е. путем увеличения в учебном плане количества дисциплин, называемых гуманитарными. Следовательно, гуманизация образования разворачивается в логике учебного предмета, учебной дисциплины, т.е. в логике передачи информации. К. Ясперс называл этот френомен - «вялая гуманитаризация». Данный способ решения проблемы - экстенсивный, при котором радикально не пересматриваются и не обновляются образовательные компоненты, ключевые компетенции, стиль взаимоотношений «преподавательстудент», образовательная среда, приобщение субъектов учебного процесса к духовным ценностям, к мировой культуре, обучению смыслов.

Традиционная парадигма трактует содержание образования как дидактически предъявляемый обучающимся «сгусток» научного знания. Такое предъявление не побуждает студентов к анализу материала, творчеству и рефрлексии. Однако реальная практика образовательного процесса разрушает иллюзии усвоения в результате подобного подхода и показывает, что содержание процесса образования не может быть только транслированием готовых фрагментов знания из учебников и учебных пособий.

Сложность гуманизации содержания образования заключается в том, что оно традиционно игнорирует личностное знание, культуру педагогического процесса. В чем же заключается суть проблемы?

Дело в том, что в рамках традиционного образования в принципе проблема гуманизации не решаема. Никак не могут быть оправданы надежды на повышение качества образования преимущественно за счет увеличения в учебном плане блока гуманитарных дисциплин, так как гуманитарная база образования не рассматривается в качестве онтологического основания образовательного процесса. Дело даже не в том, что поиск ответов на вопросы гуманизации сдерживается довольно распространенным мнением: «Нам нужны интеллектуалы - люди, которые исповедуют прагматику, а не интеллигенты, занимающиеся метафизикой и поэтикой бытия». Заявленный в полемике этот тезис отражает основную позицию значительной части преподавательского корпуса.

Для гуманизации учебного процесса не столь важно, по какой дисциплине - гуманитарной или естественнонаучной - происходит усвоение того или иного знания. По большому счету не существует самих по себе гуманитарных или негуманитарных знаний. Знания становятся таковыми в отношении человека к процессу познания в соответствии с гуманитарной или технократической образовательной моделью. Существует единственный критерий, который определяет, насколько любое знание о познающем объекте является гуманитарным: 
обретает или нет оно личностный смысл. Гуманитарные знания - это знания субъективные, имеющие эмоциональный оттенок: негуманитарной может быть литература либо география, а математика может быть вполне гуманитарной. Области познания: технократическая либо гуманитарная - однозначно не определяют характер процесса познания. Априори не существует познания гуманитарного; не область познания, а подход является индикатором гуманизации. Парадоксальным кажется наше утверждение о том, что гуманитарные знания могут оказаться негуманитарными, не соответствующими «гуманизации». «Образование без души убивает душу»,- утверждает известный психолог Зинченко В. П. [4].

Традиционный подход, назовем его «технократический круг», по которому движется и «гуманитарный» в своей предметности учебный процесс, разрывает стиль педагогического мышления. Гуманизация педагогического процесса дает о себе знать, пробивая себе дорогу в опыте личностно-ориентированных преподавателей [3]. Для такого рода преподавателей занятия не только фрагмент учебного процесса, педагогическое событие, но и со-бытие, совместная деятельность и «проживание» индивидуальностей в горизонте личности. Смысл, как личностное образование субъектов педагогического взаимодействия, к учебному процессу может существовать только на рубеже двух сознаний, двух личностных смыслов, в драматургии педагогического действа как взаимного, равноправного мыслетворчества между ними в системе координат стиля инновационного мышления: сотрудничества, диалогичности, взаимопонимания, рефлексивности, эмпатии [6].

Для преподавателя важна направленность на Другого, т.е. на студента, именно направленность задает ориентиры профессионального педагогического самосознания, мышления и рефлексии, что выражается в способности к самостоятельному ценностно-смысловому самоопределению, которое способствует самореализации обучающихся. Учебный процесс - это прежде всего личностные взаимоотношения субъектов, которые выражают свою сопричастность через ценности и смыслы образования, через многомерную сложность субъективного мира человека. В этом случае социально-ролевое воздействие трансформируется в межличностное равноправное взаимодействие.

Преподаватель сумеет осуществить проектирование собственной деятельности и личностно ориентированный подход, лишь исходя из собственных ценностей и смыслов, построенных на гуманистических основаниях [9].

Мы разработали модель гуманизации образования, включающую в себя следующие компоненты:

формирование гуманистической позиции у субъектоа образовательной деятельности; 
- $\quad$ формирование и развитие фрасилитативных, наставнических установок у преподавателей вуза;

- изменение среды учебно-педагогического взаимодействия;

- разработка и внедрение технологий и приемов обучения, «центрированных» на студенте;

создание и полноценное функционирование психологической службы в вузе.

Одним из основополагающих компонентов в нашей гуманистической модели образования является компонент фрормирования гуманистической позиции. Реализация этой модели способствует развитию нравственноценностной, мотивационно-смысловой сфер, субъектного типа взаимодействия, развитию структурно-регуляторных механизмов целенаправленной деятельности.

Гипотезы исследования заключается в предположении о том, что:

1. существуют различия в ценностях, связанных с личностной и профессиональной самореализацией, у студентов городского и сельского населения;

2. существует связь уровня сформированности гуманистической позиции студентов с их мотивационно-волевыми качествами, целевой установкой на осмысление материала, отсутствием академических умений работы;

3. существует связь параметров сорормированности готовности преподавателей к проектированию гуманистически ориентированной образовательной среды, предполагающей информационно-организационную подготовку, в умении проектировать образовательную среду с личностной сформированностью таких компонентов «Я-концепции», как креативность, интенциональность, аутентичность, стремление к самоактуализации .

Целью нашего исследования является выявление готовности субъектов образовательной деятельности к гуманизации, личностно ориентированной деятельности. Мы провели исследование со студентами РАУ в количестве 296 человек по выявлению ценностных ориентаций, социально-психологических характеристик личности преподавателя и студента. Для выявления готовности преподавателей к проектированию личностно-центрированной образовательной среды мы использовали: анкету по определению уровня готовности преподавателя к проектированию гуманистически ориентированной среды вуза; опросник инновационной готовности для определения уровня сфрормированности гуманистической позиции студентов, а также методика «Ценностные ориентации М. Рокича».

Результаты исследования показывают, что армянская молодежь сохранила ценности, культуру и традиции собственного народа, а именно семьи, 
уважение к старшим, добра и справедливости, ценности труда, образования, независимости, морально-нравственных принципов, патриотизма и религиозности. Возможно, продиктованная социально-экономическими условиями необходимость выжить, способность самосохранения усилили направленность на удовлетворение собственных, личных потребностей. По результатам проведенных нами исследований, ценности профессиональной самореализации значимее ценностей личной самореализации. У студентов РАУ, которые проживают в городской и сельской местности, ведущие инструментальные ценности незначительно различаются. Различия кроятся в мотивировании, а именно - в образованности как ценности, в возможности следования и достижения профессиональных и жизненных целей, в том числе профессиональной карьеры и материального благосостояния. Однако для городских жителей важнее не только быть профессионалом, но и проявлять высокую нравственную, гражданскую позицию. У сельских жителей специфическая социальная ситуация: у них более силен Институт семьи, приобщенность к этнокультурным традициям, национальным обычаям, к труду. Из инструментальных ценностей доминируют ценности принятия других, незначительно выражены ценности профессиональной самореализации.

Данные проведенных нами исследований и их анализ приводят к следующим выводам:

1. Студенты недостаточно адекватно сознают особенности обучения в вузе. На младших курсах не понимают специфики вуза и не в состоянии связать ее с возросшей самостоятельностью, с необходимостью самоконтроля, саморегулируемого обучения.

2. Было обнаружено, что трудности в учении студенты связывают преимущественно с недостатками мотивационно-волевых качеств (неорганизованность, отсутствие силы воли, неустойчивость внимания и настроения).

3. Анализируя полученные результаты, можно констатировать незнание рациональных способов и приемов учебной работы, конкретных способов выполнения учебных действий, отсутствие академических умений работы с огромным массивом учебного материала.

4. У большинства студентов отсутствует целевая установка на осмысление материала в процессе его усвоения.

5. У значительной части студентов установлено отсутствие установки на самостоятельное исследование и критический, творческий анализ проблемы в процессе усвоения материала.

6. Формирование успешной учебной деятельности зависит от умения ставить и решать творческие задачи.

7. Можно констатировать стремление студентов развить: а) нравственные качества - отзывчивость, заботливость и т.д.; б) самостоятельность; в) трудо- 
любие и усидчивость; г) уверенность; д) профессионально важные психологические качества; е) эмоциональную устойчивость; ж) уверенность. Обследование студентов показало, что система нравственного знания не имеет глубокого смыслового наполнения.

По параметру сорормированности готовности преподавателей к проектированию гуманистически ориентированной образовательной среды мы выделили компоненты: 1. мотивационно-ценностный, 2. когнитивный, 3. творческий, 4. операционально-деятельностный, 5. оценочно-рефлексирующий, которые мы выявили по опроснику. По результатам опросника доминируют операционально-деятельностный (50\%), когнитивный (25\%), оценочно-рефлексирующий (14\%) компоненты, минимально выражены: творческий (4\%), мотивационно-ценностный (7\%) составляющие.

Система психокоррекционных занятий в форме специального тренинга в значительной степени окажет влияние на конструктивные изменения в уровне развития профессионального самосознания преподавателей. Отработка способов преодоления трудностей педагогической деятельности и обучение приемам самоконтроля и саморегуляции в процессе психологического тренинга могут стимулировать развитие поведенческого компонента в структуре профессионального самосознания преподавателей. В процессе социально-психологического тренинга можно выявить динамику «Я-концепции» по результатам методики самооценок.

Результаты проведенных исследований свидетельствуют о необходимости выявления параметров сорормированности готовности преподавателей к проектированию гуманистически ориентированной образовательной среды, предполагающей информационно-организационную подготовку, умение проектировать образовательную среду, а также личностную сформированность таких компонентов "Я-концепции», как креативность, интенциональность, аутентичность, стремление к самоактуализации. Исследование характеристик личности позволило нам определить «вектор» развития личности - принятие ценностей других и своего «Я» - ценностей творчества, свободы выбора, ответственности - ценностей самоактуализации. Этот вектор развития определил путь самосовершенствования и личностного роста. Процесс объективации принципов психологической готовности преподавателей к личностно-развивающему взаимодействию может быть обеспечен путем создания оптимальных условий, адекватных гуманистической модели образования.

Процесс гуманизации образования является сложным динамичным явлением, в сущности, личностно-профессиональным образованием, направленным на осуществление преподавателем личностно-развивающей деятельности по созданию ситуаций, способствующих интегральному развитию личности студентов и в то же время самосовершенствованию личности самого 
преподавателя в целях раскрытия потенциальных творческих способностей и стимулирования самопознания и познания окружающей реальности.

\section{Литература}

1. Берберян А. С. Психология высшего образования в контексте гуманизации. Учебное пособие. - Прага: Vedecko vydavatelske centrum «Sociosfera -CZ. 2014. 288 c.].

2. Берберян А. С. Экзистенциально-гуманистическая психология как фундаментальное основание концепции личностно-центрированного обучения в системе высшего образования. Монография. Прага: Vedecko vydavatelske centrum «Sociosfera -CZ., 2018. 299 c

3. Бойко Л. И. Трансформация функций высшего образования и социальные позиции студенчества // Социол. Исслед. 2002. №3.

4. Зинченко В. Д. Размышления о душе и ее воспитании Международном симпозиуме “Духовность детства", г. Мачида (Япония) 21-22 августа, 2001 г. http://psychlib.ru/mgppu/Zro-001/Zro-001.htm\#\$p3

5. Лаврентьев Г. В. Инновационные обучающие технологии в профессиональной подготовке специалистов / Г.В. Лаврентьев, Н.Б. Лаврентьева. 4.1.- Барнаул: Изд-во Алт. ун-та, 2002. - 156с.

6. Ляудис В. Я. Инновационное обучение: стратегия и практика. - М., 1994.

7. Сенько Ю. В. Гуманитарные основы педагогического образования: Курс лекций : учеб. пособие для студ. высш. пед. учеб. заведений. - М., 2000.

8. Смирнов С. Д. Психология и педагогика для преподавателей высшей школы. - М: Издательство МГТУ им. Баумана. 2014, 423 с.

9. Rogers C. R. On Becoming a Person. - Boston: Houghton Mifflin, 1961.

10. http://www. parliament.am/legislation.php?sel=show\&ID=1494\&lang=rus Закон РА «Об образовании».

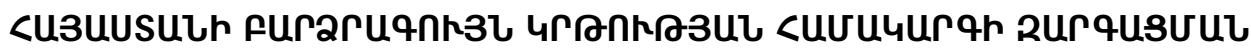

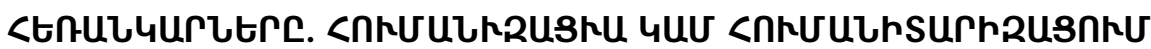

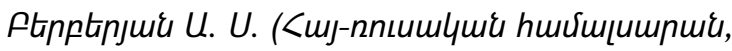

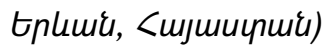

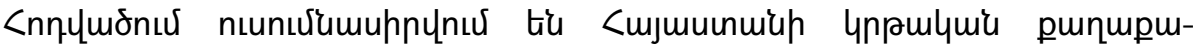

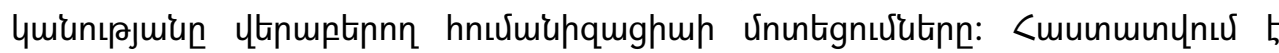

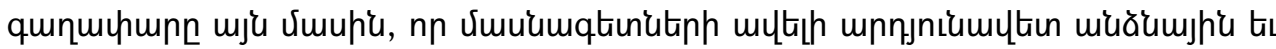

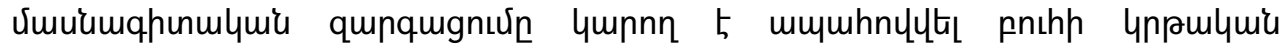

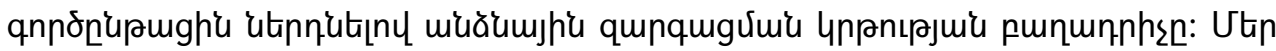

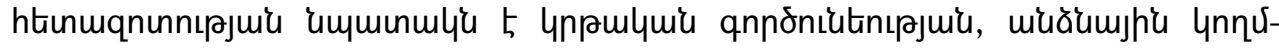




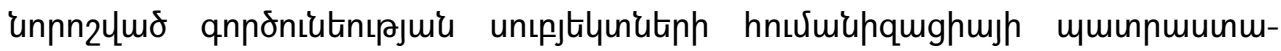

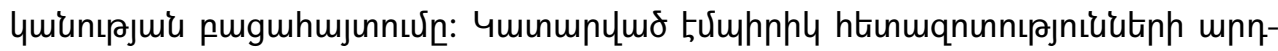

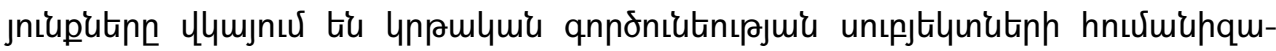

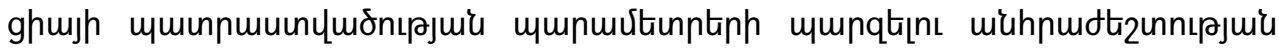
vimupin:

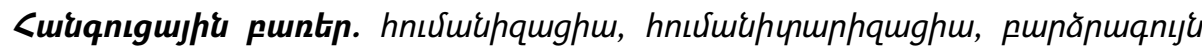

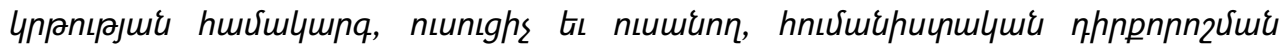

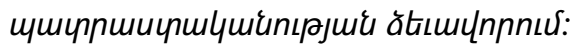

\section{PERSPECTIVES OF DEVELOPMENT OF THE HIGHER EDUCATION SYSTEM OF ARMENIA: HUMANIZATION OR HUMANITARIZATION?}

Berberyan A. S. (Russian - Armenian University, Yerevan, Armenia)

The article examines humanistic approaches to Armenia's educational policy. The idea is stated that more productive personal and professional development of specialists can be ensured by introducing the component of personal development education into the educational process of the university. The purpose of our research is to identify the readiness of subjects of educational activity for humanization, personally oriented activities. The results of the conducted empirical studies testify to the need to identify the parameters of the preparedness of the humanistic position of the subjects of educational activity.

Keywords: humanization, humanitarization, the system of higher education, teachers and students, the formation of readiness for a humanistic position. 